\title{
Customer-Labor Substitution: Evidence from Gasoline Stations
}

\author{
by \\ Emek Basker \\ U.S. Census Bureau \\ Lucia Foster \\ U.S. Census Bureau \\ Shawn Klimek \\ U.S. Census Bureau
}

CES 15-45 December, 2015

The research program of the Center for Economic Studies (CES) produces a wide range of economic analyses to improve the statistical programs of the U.S. Census Bureau. Many of these analyses take the form of CES research papers. The papers have not undergone the review accorded Census Bureau publications and no endorsement should be inferred. Any opinions and conclusions expressed herein are those of the author(s) and do not necessarily represent the views of the U.S. Census Bureau. All results have been reviewed to ensure that no confidential information is disclosed. Republication in whole or part must be cleared with the authors.

To obtain information about the series, see www.census.gov/ces or contact Fariha Kamal, Editor, Discussion Papers, U.S. Census Bureau, Center for Economic Studies 2K132B, 4600 Silver Hill Road, Washington, DC 20233, CES.Papers.List@census.gov. To subscribe to the series, please click here. 


\begin{abstract}
Employment by gasoline stations increased between 1977 and 1992, a period during which many stations converted from full-service to self-service pumps, outsourcing to customers tasks previously performed by employees. Applying several identification strategies to establishmentlevel data from the Census of Retail Trade over this period, we show that self-service stations employ approximately 0.4 fewer workers per pump. At the same time, stations that adopted self service expanded their size and diversified operations by adding convenience stores, mitigating the job-loss impact of self service.
\end{abstract}

Keyword: Customer-labor substitution, retail, gasoline station, self service, full service, outsourcing

JEL Classification: D22, D24, J23, L81

Comments welcome. Any opinions and conclusions expressed herein are those of the authors and do not necessarily represent the views of the U.S. Census Bureau. All results have been reviewed to ensure that no con dential information is disclosed. We thank Andrea Shepard, Ivan Png, and David Reitman for the Lundberg data; John Nogle for help with historic Census of Retail Trade data; and Chris Adams, Phillip Antopitov, Saku Aura, David Autor, Randy Becker, Roger Betancourt, John Haltiwanger, Russell Hillberry, Henry Hyatt, Ron Jarmin, Richard Kneller, Mark Lewis, Florin Maican, Kristin McCue, Peter Mueser, Matilda Orth, Ivan Png, Henry Schneider, Jim Spletzer, Patrick Warren, seminar participants at IFN-Stockholm, Bureau of Economic Analysis, the 2015 IIOC (Boston), the 2015 BLS-Census Workshop, and the 2015 Comparative Analysis of Enterprise Data (Istanbul) for helpful comments and conversations. Contacs: emek.m.basker@census.gov; lucia.s.foster@census.gov; shawn.d.klimek@census.gov. 


\section{Introduction}

Public discourse has often included a concern that automation and labor-saving technologies destroy jobs, particularly for unskilled and semi-skilled workers, yet employment in sectors experiencing rapid technological innovation and adoption has often held steady or even increased. For example, Bessen (2015) observes that aggregate employment in banks has increased despite the proliferation of automated teller machines (ATMs). Likewise, em-

ployment by gasoline stations increased between 1977 and 1992, a period during which the fraction of stations with self-service pumps increased from $40 \%$ to $80 \%$. These findings are puzzling because in both cases, technology has facilitated the substitution of paid workers by customers.

We use a case-study approach to examine the transformation of gasoline stations and the effects of integrating customers into the production function. Using establishment-level data from the Census of Retail Trade (CRT) over the period from 1977 to 1992, we show that self-service gasoline pumps did, in fact, reduce employment: every pump converted reduces a station's labor requirements by approximately 0.4 workers. This estimated reduction, however, is considerably mitigated when we allow for indirect effects of self service on station employment. Self-service stations are larger, open longer hours, and more likely to have convenience stores, all of which are associated with higher employment.

Since the adoption of self-service pumps is potentially endogenous to labor demand, as well as to the choice to include a convenience store or repair shop in the station, we use instrumental-variables specifications to identify the employment effects. Our identification strategies vary with the specification. In cross-sectional regressions we use self-service bans (in effect in New Jersey, Oregon, and a handful of local jurisdictions in New York and Massachusetts throughout the sample period) to identify stations with no self-service option. We also use a fuzzy regression-discontinuity design that limits the analysis to stations on the borders of New Jersey and Oregon. In panel regressions with station fixed effects we cannot use self-service bans, since we observe very little variation in these over the sample period. 
Instead, we use the interaction of the self-service ban indicator and a linear time trend as an instrument. This identification strategy exploits the fact that in 1977 pump configuration in New Jersey and Oregon was not very different from that in other states, because self service was only at its incipience. By 1992, the number of self-service pumps had increased dramatically in stations not subject to self-service bans, while remaining essentially zero at stations in jurisdictions that enforced a ban.

The technology we study is special in that it does not automate a task; rather, it enables the customer to take it over from the worker. Customer-labor substitution is increasingly common in tasks ranging from product design and assembly to advertising and customer service, and understanding its effects is critical to understanding trends in both employment and productivity in the retail and service sectors. In addition to replacing employees in gasoline stations and banks, customers increasingly book travel online without the aid of a travel agent and check in using automated kiosks at airports; check out at the supermarket "self-checkout" lines; use tablets to order and pay at restaurants; and access customerservice functions online or through an interactive voice response telephone call. ${ }^{1}$ In these and other settings, customer-labor substitution is a solution to the problem of automating tasks that are resistant to computerization. These manual tasks have proven challenging to automation and computerization because they require "situational adaptability, visual and language recognition, and in-person interactions" and "must be produced and performed largely on-site or in person" (Autor, 2015, p.12). ${ }^{2}$ Although a person is needed to perform the task, that person need not be an employee. Indeed, the one person who is guaranteed to be on site at the time of the transaction and to understand the customer's wishes and needs is the customer herself. In the specific context of gasoline stations, the self-service

\footnotetext{
${ }^{1}$ In the terminology of Betancourt (2005), customer-labor substitution may also be associated with a reduction in the distribution service ambiance. It is also called "co-production" (Lindbeck and Wikström, 2003) or "cost shifting" (Betancourt, 2005).

${ }^{2}$ For a further discussion on the ability of computers to automate mechanical work, see Autor, Levy, and Murnane (2002, 2003); Brynjolfsson and McAfee (2014); Autor (2015).
} 
revolution may have been motivated by improvements in car quality, increases in consumers' value of time, and profit opportunities for larger-scale operations and bundled convenience stores and gas stations.

The paper contributes to a broader literature on the role technology and automation play in employment dynamics. Most of the recent literature on the impact of technological innovation on employment outcomes has focused on the impact of digitization on employment and productivity. For example, Basker (2012) examines within-establishment laborproductivity growth among supermarkets in the 1970s and 1980s and finds that adoption of a new technology, checkout scanners, also increases labor productivity, and Goldmanis, Hortaçsu, Syverson, and Emre (2010) find that, although travel-agency employment declined throughout the diffusion of the Internet, it did not decline disproportionately in areas with more online transactions. A bit further afield, Graetz and Michaels (2015) study adoption of industrial robots, and find that automation reduces labor input and increases labor and total-factor productivity. These findings all suggest that firms that adopt labor-saving technolo gies tend to expand in various directions which may, in turn, preserve employment.

The paper also contributes indirectly to a broader discussion on productivity measurement, particularly in retail and services. Retail productivity is hard to measure because output is multi-dimensional (see Ratchford, forthcoming, for a general discussion); in the language of Betancourt (2005), retailers offer not only explicit goods for sale but also "implicit distribution services," which are fundamentally unmeasurable (p. 6). In addition, unlike in the manufacturing sector, capital is typically measured as square footage, or not at all; infrastructure and other capital investments are rarely, if ever, included in retail-productivity calculations. Customer-labor substitution adds a dimension to the measurement problem by introducing a non-measured component into both output and inputs. The difficulty is not simply that customers participate in the production of final goods but that the nature of their participation has changed over time. If we think of the customer's work as another input into the production function, customer-labor substitution means that we are completely missing 
information on one input. If we think of the customer's work as a component in total labor, then customer-labor substitution (or more precisely, customer-worker substitution) means that we are mismeasuring the labor input. In either case, the aggregate input measure is biased downwards and this bias increases as more stations adopt self-service technologies. Thus, true productivity may increase, particularly due to a reduction in idle time, but measured productivity increases disproportionately more. Moreover, the (multi-dimensional) output itself has changed as one of the bundled services (an attendant delivering gasoline into the customer's car) has disappeared.

We provide background on self-service adoption and related trends in the gas-station sector in Section 2. We describe the datasets used in the analysis in Section 3. Our regression specifications, identification strategies, and estimates of the employment effect are in Sections 4 and 5. Section 6 concludes.

\section{Background on Self-Service Gasoline Stations}

The self-service format in gasoline stations has been traced to a Urich Oil station in Los Angeles in 1947 (Reid, 1984). The same source estimates that only one percent of gas stations offered self-service pumps in 1969. The Census Bureau started collecting information on selfservice options at gas stations in 1972. (Our establishment-level data start in 1977.) Table 1 provides summary statistics from published Census of Retail Trade tables for 1972, 1977, 1982, 1987, and 1992. Over this period, according to published tables from the Census of Retail Trade (CRT), the share of US gasoline stations providing some self-service sales of gasoline increased from $8 \%$ to $80 \%$.

The reasons for the spread of self service are complex and, for the most part, beyond the scope of this paper. However, we would be remiss if we did not mention the likely role of two oil shocks, one in 1974 and one in 1979, in the acceptance of self service: the income effect of higher gasoline prices increased demand for options that lowered the price, however 
marginally. At its peak in 1981, the real price of crude oil was more than four times the level from 1972.

Under the Standard Industrial Classification (SIC) system, which was used until 1997, most gasoline stations were included in SIC 554, for which published statistics exist. However, convenience stores with gasoline stations - in other words, establishments whose primary business was operating a convenience store - were classified under SIC 541130 and rarely tabulated separately from other convenience stores. As the business model shifted from gasoline stations without convenience stores to combination gas station/convenience stores, this group became relatively more important. We have tabulated these from the micro data described in the next section. Over time, these stations increased from a negligible $3 \%$ of all stations to $18 \%$, so that excluding them dramatically exaggerates the decline in the number of gas stations over this period. Due to the decline in the number of stations and despite the increased popularity of the self-service format, although total employment in this sector fell from 1972 to 1982, employment per station increased. (The average employment numbers refer to published data for SIC 554 only.)

Attendants in full-service stations did much besides pumping gasoline and collecting payment; they also checked oil and belts, repaired flat tires, and more. ${ }^{3}$ Today, self service has two components: pumping the gasoline and paying for it. This paper focuses on the first component, which was measured by the Census Bureau over two decades. This innovation required that manual pump counters be replaced with digital ones that conveyed the sale amount to the cashier sitting in a booth or store. Pay-at-the-pump technology, which is central to the self-service experience today, diffused towards the end of our sample period and into the mid- and late 1990s. The earliest reference we have found to the payment

\footnotetext{
${ }^{3}$ In a children's book from 1972, an attendant named Jim describes his job: "Sometimes I prepare a charge slip for a credit-card customer. I set up displays of oil and tires, and keep a count of those items. I provide highway maps and keep candy bars for hungry travelers" (Baker, 1972, p. 23). A workbook for aspiring gas-station attendants from the same era includes instruction on these tasks as well as on checking gasoline inventory (Clarion House, 1968).
} 
technology is from 1983, halfway through our sample. ${ }^{4}$ But the technology did not catch on immediately; as of 1993, after the end of our sample, the leading installer of card readers, Mobil Corp., had readers installed in fewer than 25\% of its stations (Solomon, 1993). Our data do not include information on whether the station has card readers available at the pump.

Two previous studies have used the self-service bans in New Jersey and Oregon, which have been in place since 1949 and 1951, respectively, to study how stations in full-service markets differ from stations in markets where both formats are allowed to exist. The first study, by Johnson and Romeo (2000), uses published state-level data from the CRT. The authors find a positive association between the percentage of stations offering self-service and both total gasoline sales and the percentage of stations selling food, and a negative correlation between the percentage of stations offering self-service and the percentage of stations with service bays. The second study, by Vandegrift and Bisti (2001), uses crosssectional station-level data from a February 2000 survey of stations in New Jersey and Pennsylvania, and finds that stations offering self-service (in Pennsylvania only) have more pumps and are more likely to have convenience stores than full-service stations, but are less likely to offer repair services. Our paper adds to these analyses by using nationwide station-level data covering four economic censuses (1977, 1982, 1987, 1992), during which most markets transitioned from having one dominant format - full service - to another self service, to study the direct and indirect effects on employment.

\footnotetext{
${ }^{4}$ In 1983, Conna Corp. of Kentucky reported planning "a computerized system that will be among the first in the nation to allow customers to use a credit card or bank card to pay at the pump without an attendant handling the transaction" (Wall Street Journal, 1983). Other companies conducted early tests in California in 1983 and in Oklahoma in 1985 (Wall Street Journal, 1983; Tulsa Business Chronicle, 1985).
} 


\section{Data}

Our primary data set is constructed from the 1977, 1982, 1987, and 1992 CRT. The CRT is a quinquennial (five-year) census of all retail establishments conducted as part of the Economic Census. We focus on gasoline stations (SIC 554110) and gasoline stations with convenience stores (SIC 554130, introduced in 1987). We refer to these, collectively, as gas stations. Longitudinal links and establishment age are provided by the Longitudinal Business Database (LBD). ${ }^{5}$ This section describes the CRT sample construction in some detail. Additional data used in our instrumental-variables specifications are described in Appendix A.1.

For each station that completed CRT form 55D (in 1977) or 5504 (in subsequent years), we have detailed data on inputs and outputs. On the input side we have information about both labor (employment the week of March 12) and capital (the number of gasoline pumps the station operates as of December 31 and, if it offers self-service, the number of those pumps that were designated for self service on December 31). On the output side we have total revenue for the calendar year broken down by product lines — such as revenue from sale of gasoline, groceries, tobacco products, auto parts, and repair services. Figure 1 shows selfservice adoption rates, by state, for the lower 48 states from published CRT tables. Although not all states are included in the publication each year due to confidentiality concerns, we are able to include stations from all states in our analysis.

We restrict the CRT sample by removing a small number of stations that provide internally inconsistent answers on the forms, for example stations that report more than $100 \%$ of their gasoline pumps are self-service, and a few stations that report being active zero months of the year or have 75 gasoline pumps or more.

We infer whether a station has a convenience store or offers repair services from revenue

\footnotetext{
${ }^{5}$ For background on the LBD, see Jarmin and Miranda (2002). The LBD starts in 1975, so station age is censored at two in 1977, seven in 1982, 12 in 1987, and 17 in 1992.
} 
reports. To be conservative, we identify a station as having a convenience store if it reports at least $\$ 1,000$ in revenues from the sale of food, alcohol, or tobacco products (1992 dollars). Similarly, we identify a station as having a repair shop by the station's reporting at least $\$ 1,000$ in receipts from repair services. ${ }^{6}$

The CRT generally does not include information on the brand name associated with each station but it also includes an identifier for the owning firm, allowing us to link stations owned by the same firm. If the firm also owns a refinery (SIC 2911), the same firm identifier is also included in Census of Manufacturing. We tag stations as vertically integrated if they belong to a firm that also operated at least one refinery in the same year. Vertically integrated stations may have different labor practices and different propensities to adopt the self-service model (Blass and Carlton, 2001; Vandegrift and Bisti, 2001).

For regression-discontinuity samples we have geo-coded the addresses of all stations in New Jersey, Oregon, adjacent counties (in New York, Pennsylvania, Delaware; Washington, California, Idaho, and Nevada) and counties adjacent to the adjacent counties (some of which are in Maryland, Connecticut, and Montana). When the CRT address is not geocodable, for example because it is a post-office box or a rural route, we use an address of the same establishment in other years, either from the CRT or from the LBD. In all, we succeeded in geocoding slightly more than half of the sample in the relevant counties.

Our outcome variable of interest is station employment. To test for robustness of the results, we have conducted all the analyses in this paper using payroll as an alternative outcome measure. Payroll has both advantages and disadvantages over employment. Among the advantages, payroll implicitly adjusts for hours of work, since the CRT does not distinguish between full-time and part-time employees. Employment is also a very "lumpy" variable,

\footnotetext{
${ }^{6}$ Economic Census data are the only source for many of the variables we use. Some variables, including employment, come from administrative sources and are extremely reliable. Other variables, including number of pumps and availability of self-service pumps, are self reported on CRT forms and may be subject to reporting and measurement error. We have a unique opportunity in this case to check a subset of the data by cross-tabulating it with another source, as detailed in Appendix A.2.
} 
particularly for small stations, and may not be continuous in the number of self-service pumps. In addition, employment is measured the week of March 12, a week which may or may not be representative of year-round employment. In contrast, payroll is sensitive to shift work and job responsibilities. As the tasks performed by gas-station employees changed, payroll may have changed even without any change in employment. ${ }^{7}$ The results were quite consistent across the two outcome measures, with payroll results somewhat noisier, so we present only the employment outcome in the current paper.

We create two subsamples of the data for different regressions, depending on the effect we are trying to estimate. Panel A of Table 2 shows summary statistics for the "direct" samples, which we use to estimate the direct labor-saving by self service; these samples include only stations with no convenience stores or repair shops. Within these, the border samples are a subset of the pooled cross-sectional data, including all stations within five, ten, or twenty miles of the New Jersey or Oregon state borders. These relatively small samples have higher average station employment but fewer pumps per station than the complete direct sample. By construction, fewer stations in these samples offer self service, since they are drawn from the border area of states with self-service bans. The direct panel sample is also a subset of the pooled sample, but is restricted to stations we observe at least twice and whose total number of pumps did not change throughout the period they are in our dataset.

Panel B shows statistics for several "full" samples. The full pooled samples includes all stations with complete valid data on the variables we use in our analysis, and includes approximately one third of all gas stations in the U.S. each year (from Table 1). The border samples and panel sample are expanded analogously.

\footnotetext{
${ }^{7}$ Payroll per worker in our sample stations averages around $\$ 13,000$ in 1992 dollars. By way of comparison, workers interviewed for the Current Population Survey's Merged Outgoing Rotation Groups (CPS-MORG) between 1979 and 1992 who reported working at gas stations and who reported their average weekly pay, earned approximately $\$ 270$ per week in 1992 dollars (averaged across all workers, regardless of number of hours worked), which translates to about $\$ 14,000$ over 52 weeks.
} 


\section{Direct Effect}

We use both cross-sectional and panel regressions to analyze the effect of self-service on station-level employment. These regressions use the direct samples.

\subsection{Cross-Sectional Regressions}

We pool all years of data to estimate cross-sectional regressions of the general form:

$$
\operatorname{emp}_{i t}=\alpha+\delta_{t}+\beta_{x} \cdot \operatorname{pumps}_{i}+\gamma_{x} \cdot \operatorname{pumps}_{i}^{s s}+X_{i t} \theta_{x}+\varepsilon_{i t}
$$

where emp is station employment (a positive integer). On the right-hand side, $\delta$ is a year fixed effect, pumps is the total number of gasoline pumps the station operates, and $\mathbf{p u m p s}^{s s}$ is the number of self-service pumps. Neither the LHS nor the RHS variables are logged as we expect a linear rather than log-linear or log-log relationship between employment and the number of self-service and full-service pumps. The coefficient $\beta_{x}$ represents the additional number of workers associated with each additional pump, and and $\gamma_{x}$ is the number of workers saved by converting that pump from full service to self service. ${ }^{8}$

In most specifications, the control variables $X_{i}$ include firm (chain) fixed effects $(\mathrm{FE})$ to control for the fact that some chains may have more- or less-labor-intensive operations (where it is not feasible to include firm FE, we replace it with a vertical-integration indicator); and an indicator for the station being at least two years old at the time of the census. Firm fixed effects capture the fact that vertically integrated firms may have different employment practices. Even among integrated firms, different organizational forms may have different employment practices; for example, company-operated stations, which are managed by company employees, may have more principal-agent problems than lesee-dealer stations,

\footnotetext{
${ }^{8}$ In a previous version of the paper, we estimated these regressions separately by year. No systematic differences in coefficient values emerged in those specifications.
} 
owned by the refiner but operated by a residual claimant. ${ }^{9}$ Controlling for station age is important because older surviving stations tend to be larger, and they are also less likely to have converted to self service. Because we use the LBD to calculate age, and the LBD starts in 1975, for consistency across samples we use an indicator for the station being at least two years old at time $t$. Most of the variation in station employment that is correlated with station age is soaked up by this indicator.

Station employment depends on many factors other than the number of full- and selfservice pumps. The limitation of cross-sectional regressions is that we can only control for a small subset of these variables, many of which are unobservable. We address this concern by instrumenting for self-service adoption with the existence of a ban on self-service stations. This instrument has very strong predictive power, with first-stage F statistic well above $10 .{ }^{10}$ A concern about this instrument is that the locations that ban self service may share other characteristics that could independently affect employment, or the bans may themselves be endogenous; we use a fuzzy regression-discontinuity design (FRD) later on, focusing on the borders of New Jersey and Oregon, to partially address this issue. Appendix B discusses first-stage estimates in detail.

The first two columns in the top panel of Table 3 show our estimates of the effect of selfservice pumps on station employment. The OLS estimate shows a per-pump labor saving of one quarter of a worker, meaning a station can reduce employment by one worker for every four pumps that convert from full service to self service. The IV estimate is larger, consistent with saving one worker by switching only 2.3 pumps to self service.

The fact that the IV estimate is larger in absolute value than the OLS estimate suggests that unobservable factors that are correlated with adoption of self service, but not the instrument, increase station employment. For example, stations may adopt self service endogenously when they increase their hours of operation; while self service reduces em-

\footnotetext{
${ }^{9}$ The taxonomy is from Hastings (2004).

${ }^{10}$ As a rule of thumb, an F statistic above 10 indicates a strong instrument (Staiger and Stock, 1997).
} 
ployment, the longer hours mitigate this effect and lead to an attenuated estimate of labor saving. Consistent with this interpretation, we find a positive correlation between a station operating 24 hours and the fraction of its pumps designated for self service in the two years (1977 and 1992) in which stations were asked about 24-hour operations; and cross-sectional OLS regression results with this added indicator as a control variable move the coefficient estimate of $\gamma_{x}$ in the direction of the IV estimate in both years. ${ }^{11}$ Stations with self service may also have higher employment because they are busier (i.e., sell more gasoline), or are more likely to face regulations that require more employees, such as laws in some cities that require an attendant on duty at all times even in self-service stations.

As a robustness check, we use a fuzzy regression-discontinuity (FRD) approach to estimate the labor-saving associated with self service. To implement this approach, we use the same IV strategy as above with a few modifications. First, we limit our sample to geocoded gas stations within a narrow band (between 5 miles and 20 miles, depending on the specification) on either side of either the New Jersey or Oregon border. Second, we add several control variables to the covariates $X_{i}$ from Equation 1. The first is the distance from the nearest OR or NJ border, interacted with the state in which establishment $i$ is located (i.e., separate distance variables for New Jersey, New York, and so on). In addition, we add five broad region indicators to capture differences in market characteristics that may affect employment. $^{12}$

The results are shown in the bottom panel of Table 3. The first three columns show OLS regressions, and the next three show FRD regressions. OLS coefficients range from

\footnotetext{
${ }^{11}$ The fraction of stations reporting 24 -hour operations rose from $10 \%$ of respondents to over $40 \%$ between 1977 and 1992. We do not report these results separately since the 24-hour indicator is itself endogenous to labor demand, and is available for only a subset of stations and years.

${ }^{12}$ We construct the regions to each encompass establishments from at least two states in a common area. These include, (a) the New Jersey/Delaware border area and nearby establishments in Maryland; (b) the New Jersey border with the Delaware Valley region of Pennsylvania; (c) the New Jersey border with Northeast Pennsylvania; (d) the New Jersey-New York border and nearby establishments in Connecticut; and (e) Oregon and surrounding areas. We have also estimated the model with narrower MSA indicators; the results were not sensitive to this specification change.
} 
-0.29 to -0.34 , depending on the distance band, and are thus similar to the cross-sectional OLS estimates. The FRD point estimates are negative, ranging from -0.14 in the five-mile sample to -0.46 in the 20 -mile sample. The five-mile estimate is statistically insignificant, although the standard error is large enough that an effect three times the size falls within its 95\% confidence interval. The ten- and 20-mile estimates, with larger sample sizes, are both statistically significant and quite similar to the cross-sectional IV result. Together, these results indicate that self-service pumps reduce employment. ${ }^{13}$

\subsection{Panel Regressions}

An alternative approach to identification is to replace the cross-sectional analysis with a panel specification. This approach has the advantage that we can include station fixed effects, capturing time-invariant unobserved differences in labor utilization across stations. A disadvantage is that our restrictions on data quality constrain the sample size of stations that are observed more than once, so the panel sample is relatively small. In addition, by construction, the panel specification includes only on continuing establishments, and does not use variation in the data due to entrants and exiters. Foster, Haltiwanger, and Krizan (2006), using data from the CRT to study labor-productivity growth in the 1990s in the retail sector as a whole, find an $11 \%$ increase in labor productivity over a decade, which can be almost entirely explained by entry of more-productive establishments and exit of less-productive ones rather than by within-establishment productivity growth. Continuing establishments may be less likely to innovate than new ones. For this reason, establishments in the panel sample may not be representative of the sector more broadly.

\footnotetext{
${ }^{13}$ Results using payroll as a LHS variable, not shown, are less clear cut. Although the cross-sectional results are consistent and imply cost saving of around $\$ 10,000$ per employee, the FRD results are not robust. One reason for this anomaly is that the prevailing wages are lower in New Jersey and Oregon communities near the state border than on the other side of the border, particularly when the other side is Manhattan and its northern suburbs.
} 
Our panel difference-in-difference regressions are

$$
\mathrm{Y}_{i t}=\alpha_{i}+\delta_{t}+\gamma_{p} \cdot \operatorname{pumps}_{i t}^{s s}+X_{i t} \theta_{p}+\varepsilon_{i t}
$$

where $\alpha$ is a station fixed effect and $\delta$ is a time fixed effect, $\mathbf{X}$ includes indicators for a vertically integrated firm and for the station being at least two years old at time $t$, and the other variables are as above.

In addition to removing stations with convenience stores and/or repair services, as in the cross-sectional analysis, we also restrict the sample to stations whose total number of gasoline pumps has not changed over the period of study. This restriction allows us to focus on stations that have maintained a fixed capital stock and that do not have convenience stores or repair services so we can better isolate the effect of converting a full-service pump to self-service, but at the cost of a much smaller sample. The inclusion of station fixed effects further limits the number of stations used to identify the coefficient of interest: only a third of the stations in the sample, or about 400 stations, experience a change in the number of self-service pumps during the sample period.

Although station fixed effects remove any unobservable time-invariant station-level differences from identifying the effect of self service on outcome variables, unobserved shocks may still affect the parameter of interest. We address this concern using the interaction of a linear time trend with the self-service ban as an instrumental variable. First-stage results are strong: with every passing census year, the number of self-service pumps in New Jersey, Oregon, and the towns in New York and Massachusetts enforcing a ban on self service diverges further from the national trend.

The third and fourth columns in the top panel of Table 3 show OLS and IV panel estimates. The OLS coefficient is smaller in the panel specification than in the cross sections, reflecting the difference between the nature of the samples and the identifying variation. The IV point estimate is even smaller, at -0.06 , and has a very large confidence interval. Given 
the small number of stations used to identify the within-station effect of self-service pumps on employment, this is perhaps not surprising. As in the five-mile FRD regression, however, the large confidence interval includes effects in the range of the cross-sectional IV result.

\subsection{Discussion}

The above regressions all aim to estimate the direct labor reduction due to self-service pumps: how many workers can a station shed when it converts the marginal pump from full service to self service? Cross-sectional estimates using self-service bans to instrument for adoption, as well as fuzzy regression-discontinuity regressions using the same instrument with fewer observations and more control variables point to a direct effect in the neighborhood of a labor saving of 0.4 workers per pump converted to self service. In Appendix $\mathrm{C}$ we report results from an alternative identification strategy that uses variation in local climate to predict adoption of self service: stations in colder climates were less likely to adopt self service during this period. The point estimate from that regression is also around -0.4 .

Panel estimates, on the other hand, tell a somewhat different story. The OLS estimate is more muted at -0.13 , and IV result, using the differential time trend in self service at states with and without self-service bans, is near zero but with a large confidence interval.

We are confident in the cross-sectional results, given their robustness to different samples and identification strategies. The difference between the cross-sectional and panel results is not due to differences between the samples but rather to the fact that the panel estimates use within-station variation rather than cross-sectional variation. ${ }^{14}$ The results are the labormarket analog of the hypothesis by Aaronson, French, and Sorkin (2013) that incumbents are constrained in their ability to adjust their capital stock. Aaronson, French, and Sorkin use this to explain why restaurant churn increases following changes in the minimum wage: only entrants can choose a capital-labor ratio that is optimized for the new minimum wage.

\footnotetext{
${ }^{14}$ When we estimate the cross-sectional specification using the panel sample, the estimates — not shown - are indistinguishable from the cross-sectional estimates.
} 
In the direct panel sample, stations are constrained to adjust their capital stocks in a very specific way - holding fixed the level of capital, measured as the number of pumps, they may only reassign full-service pumps to self-service. What the panel results show, consistent with the findings of Foster, Haltiwanger, and Krizan (2006), is that they may not be able to easily adjust their labor demand.

To see how many jobs in the aggregate economy these efficiency gains imply, we perform the following back-of-the-envelope calculation. About 400,000 pumps were converted from full service to self service between 1977 and 1992. ${ }^{15}$ If each of these is associated, conservatively, with a loss of $40 \%$ of a job, the direct job loss due to the implementation of self service is 160,000 jobs, or nearly a quarter of 1977 employment.

\section{$5 \quad$ Full Effect}

\subsection{Motivation}

The direct effect is a narrow one. We next ask what the effect of such a conversion would be if stations had more margins on which to adjust: for example, if they could, along with changing the service level, also add pumps, open or expand a convenience store, or close or cut back a repair shop. Increasingly, gas stations have become coupled with convenience stores. This gas station-convenience store pairing replaces the previous model of gas stationrepair shop combinations. This change in the breadth of product assortment offered by gas stations may change the price consumers are willing to pay for gasoline, independent of the direct effect of self service, and therefore affect employment indirectly as well as directly. ${ }^{16}$

\footnotetext{
${ }^{15}$ Published Census Bureau estimates of the number of gasoline pumps in operation in 1977 is 765,298 , of which 218,083 were self service. By 1992, the published total, which includes pumps for other automotive fuels (including diesel) was 837,963, of which 635,210 pumps were self service. We do not know how many of the self-service pumps were diesel pumps.

${ }^{16}$ The change in station characteristics is reflected in the description of SIC 554 in Census publications. In 1972, 1977, and 1982, the description was given as "Establishments primarily selling gasoline and automotive lubricants. Usually these establishments also sell tires, batteries, and accessories, and perform minor repair work and services. Establishments called garages but deriving more than half of their receipts from the sale
} 
Allvine and Patterson (1974) explain the complementarity between convenience stores and self-service with the fact that a self-service station still needs to have an employee on duty to handle payments and problems, but that employee is under-utilized; the marginal labor cost of a convenience store is therefore very low for such stations. Lawrence (1984), on the other hand, argues that convenience stores were needed to cross-subsidize lower retail margins in competitive gas stations. Finally, Lambert (2015) speculates that convenience stores became popular because self-service customers had to come into the booth or office; once inside, they were easy targets for convenience items. This view is consistent with any model of shopping involving search or transportation costs, but it does not explain why convenience stores persist in later years following the introduction of pay-at-the-pump technology.

Station size may have increased with self service because it is complementary with convenience stores rather than because it is directly complementary with self service. Once a convenience store is bundled with the gas station, a larger station provides a larger customer base for the convenience store. Since the convenience-store clerk is often idle, and impulse products like candy bars and cigarettes are sold at a markup, increasing the flow of customers increases producer surplus without increasing labor costs.

The concomitant decline in the bundling of gas stations with repair services has been explained by improvements in cars, which lengthened the time intervals between required oil changes and reduced the need to check belts, hoses, and fluids at every fill-up; moreover, newer models, starting in the 1980s, included malfunction indicator lights to let drivers know

of gasoline and automotive lubricants are included." In 1987 and 1992, the second sentence was changed to "These establishments frequently sell other merchandise such as tires, batteries, accessories, and other automobile parts or perform minor repair work." This change from "usually" to "frequently" reflects the decline in gasoline station/repair shop combinations. In addition, a final sentence was added to the description starting in 1987: "Gasoline stations combined with other activities, such as grocery stores, convenience stores, or car washes are classified based on primary activities as determined by sales," reflecting the emergent convenience store complementarity. In 1992, for the first time, a subset of SIC 554 was classified as "Gasoline/convenience food stores": "Establishments primarily engaged in the retail sale of gasoline and automotive lubricants and also sell a line of convenience store items such as milk, eggs, bread, beer, pet food, detergents, etc." 
their oil needed to be checked. Describing the 1970s, gas-station owner David Nassaney recalls: "We would always ask the customer if they wanted us to check their oil and water [.... It was easy to bring in extra income just by opening the hood of a car" (Nassaney, 2013, p. 12). In addition, Oi (1992) points out that non-price competition between automobile dealerships and the provision of warranties have shifted many repair services to automobile dealerships (p. 186). Oi also notes the increase in specialty repair shops such as Jiffy Lube. With the rise of vertically integrated stations, principal-agent issues make repair shops at gas stations a less attractive feature (see Blass and Carlton, 2001). Finally, because the arrival rate of customers is variable and lumpy, a gas station attendant in a full-service station may have been idle a significant portion of the day; working on cars during those idle times could be a way to bring in extra revenue at relatively low cost. Self-service pumps eliminate the idle time by eliminating the attendant.

\subsection{Results}

To see what effect these endogenous station characteristics have on employment we repeat the regressions from Section 4, this time using the full sample of stations. We do not control for the presence of repair services or convenience stores or for the total number of pumps at the station because these choices are endogenous. The results are reported in Table 4.

Because of the very large number of firms in the pooled cross-sectional regressions, we are unable to estimate a full set of chain fixed effects in the cross-sectional IV specifications, so in the cross-sectional regressions we replace the chain FE with an indicator for vertically integrated stations. We have also eliminated the control for total number of pumps, since we treat it as an endogenous outcome variable in this setting. In all other respects the cross-sectional regression equation is identical to Equation (1).

The cross-sectional OLS coefficient, shown in the left-most column in the upper panel, is now positive: instead of saving 0.4 workers per pump, it now indicates that stations with more self-service pumps actually have more employees. In other words, stations that adopt self 
service tend to undo their labor saving - and then some - by using additional labor in (new or enlarged) convenience stores and expanded stations. These results are consistent with the notion that convenience stores are complementary with self-service stations, although they do not allow us to test for the mechanism behind this relationship. ${ }^{17}$

The IV estimate, however, is still negative, if only one third of the size of the direct effect estimated with the same identification method. The sign difference between the OLS and IV results is consistent with selection of large stations into self service.

The bottom panel of Table 4 shows OLS and FRD results using the border sample. Because this sample is smaller than the cross-sectional sample, we continue to control for chain FE in these specifications, and find that both the OLS and the FRD results are not very different from the ones in the direct sample, although they tend to be slightly (if not significantly) less negative (more positive).

The last two columns in the top panel of Table 4 show the panel OLS and IV estimates. As with the pooled cross-sectional sample, the OLS estimate is positive and significant and the IV estimate is negative and significant. The increased power in the IV estimate relative to the direct panel sample is due to two factors. First, the full panel sample is thirty times larger than the direct panel sample. Second, this sample also has a much higher rate of self-service adoption: fully two-thirds of the full sample, or about 24,000 stations, changed (generally, increased) the number of self-service pumps they operated over this period.

Taken as a whole, the full-sample estimates of the effect of self-service pumps on employment, allowing stations to adjust on multiple margins including station size (number of pumps) and service composition (repair, convenience store) are smaller than the directsample estimates, but also exhibit wider dispersion. Along the state borders of New Jersey and Oregon, the full effect is not noticably smaller than the direct effect, suggesting that

\footnotetext{
${ }^{17}$ We cannot test directly for an effect of self service on convenience stores. OLS results show a positive correlation between a station's intensity of self-service implementation and the presence of a convenience store, but we have not found any instruments that can predict the presence of a convenience store or a repair shop holding constant the station and chain characteristics for which we currently control.
} 
self-service stations competing head-to-head with full-service stations may be less likely to adjust on multiple margins. The pooled cross-section and panel effects, though, are smaller, ranging from -0.22 to -0.13 . (Appendix $\mathrm{C}$ reports the estimate from an alternative crosssectional identification strategy at a statistically insignificant -0.12.) These results are consistent with the findings of Johnson and Romeo (2000) and Vandegrift and Bisti (2001) that self-service stations are larger, more likely to have convenience stores, and less likely to offer repair services.

Taking the IV estimates from the full-effect cross-sectional sample seriously implies that the conversion of 400,000 pumps from full to self service decreased gas-station employment by approximately 52,000 jobs, accounting for increased employment in convenience stores attached to gasoline stations, the reduction in repair-shop/gas-station combinations, and the growth in station size. Although this estimate does not go all the way towards explaining the increase in gas-station employment over the period we study, it is considerably smaller than the direct-effect estimates in Section 4.

\subsection{Productivity Measurement}

Our results highlight challenges in productivity measurement introduced by the increasing adoption of self-service in retail trade. ${ }^{18}$ On the input side, the direct-effect specifications show that without a measure of the contribution of customers, we underestimate the labor input. We need to capture the total labor inputs for self-service gasoline in order to correctly measure productivity. This point is not new; Oi (1992, p. 162) argues that the "theory of production has to be augmented by including the inputs of consumers and producers in measuring the rate of technical progress." Our estimates of labor saving provide a starting point for a correction that incorporates foregone as well as observed labor inputs.

\footnotetext{
${ }^{18} \mathrm{~A}$ parallel but opposite problem occurs in industries that offer increased services, such as prepared packaged foods and delivery services that save consumers the need to go to the grocery store, select, and carry home their groceries. In these cases, workers are performing tasks previously done by households.
} 
On the output side, the introduction and expansion of self service creates challenges for correctly measuring the output of gas stations. The literature on productivity measurement has distinguished between a physical-quantity-based productivity measure (e.g., TFPQ) and revenue-based productivity measure (either TFPR, if both capital and labor are known, or real revenue per unit of labor input, as in Foster, Haltiwanger, and Krizan, 2006). In the retail sector, where quantity is typically not measurable, all studies of which we are aware have used revenue-based measures of productivity. In this sense gasoline retailing is unique, because sales volume, and not just revenue, is collected in the CRT. Moreover, the output of gasoline stations is relatively homogeneous and easy to measure. This suggests that it may be possible to create a physical productivity measure using volume output as is done by Foster, Haltiwanger, and Syverson (2008) for eleven homogeneous manufacturing products (including gasoline). However, the transition from full service to self service changes the meaning of "a gallon of gas" when the gasoline is unbundled from the service component. Additionally, our results from the full-effect specifications show that the output of gas stations is now not only filling up a gasoline tank but may include complementary products via a co-located convenience store.

Researchers may be tempted to rely instead upon the value measure of productivity because it embodies this service differential in the lower price for self-service gasoline and captures other amenities such as hours and convenience-store features. Haltiwanger (forthcoming, p. 7) notes that a revenue measure of productivity is preferable to a physical measure of productivity when firms do not have market power but produce goods of differential quality, because the prices embedded in the revenue-based measure implicitly adjust for differences in quality across firms. ${ }^{19}$ Unfortunately, gas stations do not meet the requirements for this approach because the difference in prices across stations reflects many things in addition to the service level, such as market power (see, e.g., Noel, forthcoming). Thus,

\footnotetext{
${ }^{19}$ For a related discussion, see also Foster, Grim, Haltiwanger, and Wolf (2015).
} 
this industry highlights both the strengths and weaknesses of both physical and revenue measures of productivity.

\section{Concluding Remarks}

Customers have always belonged in the retailer's production function: without them, the store "could not produce a transaction which is the raison dêtre for its existence" (Oi, 1992, p. 168). The customer is unique among the inputs in that she is unpaid, or paid implicitly, for example in the form of lower prices or increased convenience.

Different from some other settings with customer-labor substitution, in which consumers are compensated only with increased convenience or shorter waiting times, if at all, gas stations compensated the customer-worker with lower prices. Borenstein (1991), using data from a large consumer survey, reports that the average premium increased "from about one cent in 1980 to nearly six cents in 1986, and then declined back to about two cents by the end of the decade" (p.1). For 1987, Shepard (1991) estimates the full-service premium in a four-county area in eastern Massachusetts at between seven and nine cents, in nominal 1987 dollars. $^{20}$ For 1982, we use data from the Bureau of Labor Statistics (BLS) and the American Chamber of Commerce Research Association (ACCRA) to estimate the average full-service premium nationwide at around ten cents in nominal 1982 dollars (about 8.6 cents in 1992 dollars). Details of this estimation are in Appendix D. ${ }^{21}$

The effects of customer-labor substitution are complex and transformative. As we show in this paper, although the direct effect is a reduction in (paid) employment, the full effect can be quite different. Table 1 shows that although the initial phase of self-service adoption, from 1972 to 1977, was associated with a decrease in employment in the sector, employment

\footnotetext{
${ }^{20}$ Massachusetts may not be representative of the national full-service premium. The state allows cities to ban self-service stations, and some cities in this four-county area did enforce such bans, as noted earlier.

${ }^{21} \mathrm{Kim}$ (2015) documents the full-service price premium in Seoul, South Korea, which is currently undergoing the transition to self service that the U.S. experienced in the 1970s and 1980s.
} 
did not fall as adoption of the self-service model rose from $40 \%$ of stations in 1977 to $80 \%$ in 1992. In SIC 554 alone, employment was essentially constant from 1977 to 1992, rising from about 673,000 to 675,000 ; it continued to rise in 1997. (It fell in 1982, a recession year, then stabilized.) In addition, employment in SIC 541130 is not available for 1977, but published CRT tables show it was around 140,000 in 1992 and 180,000 in 1997. This increase in employment took place despite the fact that the implementation of an additional technology — credit-card readers at the pump — eliminated customers' need to interact with employees altogether in most transactions. One station employee is quoted by the Wall Street Journal saying that the having card readers at the pump "almost takes your job away.... It's real lonely" (Solomon, 1993).

Employment in this sector has increased despite a labor saving of approximately 0.4 workers per pump in part because self-service adoption induced a change in the business model: stations increased in size, divested themselves of repair shops, added convenience stores, and increased their hours of operation. These changes likely transformed the skill set of workers as they have taken on new tasks. Bessen (2015) similarly attributes the preservation of teller jobs to changes in the underlying business model. As the number of tellers required per branch fell, banks responded by opening more branches and those tellers that remained became part of the "relationship' banking team" (p.17). An exciting development in self-service is currently being played out in drugstores where we see the rise in self-checkout with the simultaneous rise in the provision of health services. We look forward to studying the impact of these transformational changes in the future. 


\section{A Data}

\section{A.1 Auxiliary Data}

Data on local self-service bans come from a variety of sources, mostly media mentions, which we have made every effort to verify using city bylaws and regulations. We use an indicator for a city or state's ban on self service as an instrument for self-service adoption. The main bans, in New Jersey and Oregon, have been in place the entire study period (and remain in place in 2015). Local bans are also in place in four Massachusetts cities (Arlington, Holbrook, Weymouth, and Upton) and in Huntington, NY. Two other New York towns, East Hampton and the Village of Patchogue, repealed their bans in the late 1980s. Although we have spent considerable time combing through township statutes, particularly in New York and Massachusetts, to determine when and where self-service bans have been in place, we make no claims about the completeness of our list of city-level bans, particularly not historically. The list is adequate for our purpose, which is to predict self-service adoption with sufficient power. Some stations in locations with self-service bans do report having self-service pumps, but this fraction is under $5 \%$, as compared with $70 \%$ over the full sample period in locations without a ban. This could reflect either measurement error or stations that are exempt from the regulation, for example, stations that serve private vehicles fleets. ${ }^{22}$

We supplement our data with data from the Current Population Survey's Merged Outgoing Rotation Groups (CPS-MORG) from the 1979-1992 waves. The data are used to capture characteristics of workers and jobs in the gas-station sector (1970 industry code 648 and 1980 industry code 621); they are not matched to the CRT. Although the CPS sample is not intended to be representative within narrow industry and occupation classifications, it is nonetheless telling that, among CPS respondents in the gas-station sector, the fraction

\footnotetext{
${ }^{22}$ Many towns have additional regulations during part or all of the study period, most commonly requiring an attendant on duty during operating hours even at self-service stations. Because these regulations are very local and often changed over time, it is impossible to fully account for them in a national study such as this one.
} 
who gave their occupation as "attendant" (1970 occupation code 623 or 1980 occupation code 885 ) declined steadily between 1979 and 1992, from about $46 \%$ to $27 \%{ }^{23}$

\section{A.2 CRT Data Quality}

We have merged the 1987 CRT observations from four counties in Massachusetts (Essex, Middlesex, Norfolk, and Suffolk) with data provided by the Lundberg survey from the first three months of 1987. The Lundberg data, which have been used by Shepard (1991, 1993) and Png and Reitman (1994, 1995), include prices at over 1,500 gas stations in these four counties. Up to 16 prices are provided for each station, representing combinations of four binary variables: full vs. self service; cash vs. credit; leaded vs. unleaded gasoline; and regular vs. premium gasoline. We code any station that posts at least one self-service price as offering self service. We then match the data with the CRT, merging on name and address. Of the 900 stations we successfully merge across the two datasets, a third (300) have complete data in the $1987 \mathrm{CRT}^{24}$ Of these, over $95 \%$ of stations that report having self-service pumps in the CRT are also recorded as having one or more self-service prices in the Lundberg file, and over $85 \%$ of stations that report not having self-service pumps in the CRT also have no self-service prices in the Lundberg file. Considering the timing is slightly different in the two datasets (the CRT is conducted at the end of the year, and the Lundberg surveys took place in the first quarter), we consider this match level very high.

\section{B First-Stage Results}

Table B-1 shows first-stage regressions results for the cross-sectional and panel samples.

\footnotetext{
${ }^{23}$ In New Jersey and Oregon the share of gas-station workers - a small sample — describing themselves as attendants increased from $43 \%$ to $60 \%$ over this period.

${ }^{24}$ All observation counts are rounded to the nearest hundred.
} 
The first two columns show results for the pooled cross-sectional samples using the selfservice ban as the instrument: first for the direct sample (excluding convenience stores and repair shops) and then for the full sample. The coefficients on the self-service bans are, as expected, negative and significant: a self-service ban is associated with fewer self-service pumps, all else constant. The coefficient in the direct sample, for example, indicates that, on average, a station in a location that imposes a ban on self service has 5.4 fewer self-service pumps than a station in a location without a ban. In both cases the F statistics are well above the rule-of-thumb threshold of 10 .

The next two columns show the first-stage results for the panel samples (direct and full). Again, the coefficients are all negative and significant, and all F statistics meet the threshold of 10 . The coefficient on the direct sample, -1 , means that, on average over a five-year period during our sample (e.g., from 1977 to 1982) the number of self-service pumps declines by approximately one in locations that are affected by a self-service ban relative to locations that are not subject to such a ban.

Table B-2 shows first-stage results for six border samples: three direct (five-, ten-, and twenty-mile bands around the New Jersey and Oregon state borders) and three full. Here again all coefficients are negative and significant, and first-stage $\mathrm{F}$ tests are all well about 10.

\section{Local Climate}

As an alternative to self-service bans, we also have a second instrument for the pooled crosssectional regressions: local climate, which works through the demand side. The idea is that demand for self-service gasoline is lower in locations with colder climates, particularly initially. In other words, it is no coincidence that self-service stations first arose in sunny Southern California. Specifically, we create a variable, freezing, which represents the fraction of the year in which the county's average temperature is below freezing. A concern about 
this instrument, which would be shared by any variable capturing local climate, is that it is strongly spatially correlated and therefore likely to be correlated with other, unobserved, spatially correlated variables. ${ }^{25}$

Data on local climate come from the National Oceanic and Atmospheric Administration (NOAA). From NOAA's National Climatic Data Center (NCDC) we obtain average daily temperatures, over the period 1971-2000, for each of 5,495 weather stations nationwide for which this variable is available. There are weather stations in each of the fifty states (but not in the District of Columbia): from a low of five in Rhode Island to a high of 369 in Texas. We count the fraction of days of the year in which the station's average daily temperature is below freezing $\left(32^{\circ} \mathrm{F}\right) .{ }^{26}$ Next, we aggregate station-level data to the county level, averaging across all stations in a county. We end up with a file covering 2,717 counties in all 50 states. Of these, 1,146 counties have zero days with below-freezing average temperatures, including all counties in Alabama, Florida, Georgia, Hawaii, Louisiana, Mississippi, and South Carolina. Among the remaining 1,571 counties, the average county has a belowfreezing average temperature $23 \%$ of the time (85 days per year). Therefore, the 25th percentile of the distribution is zero days below freezing, and the 75 th is about $25 \%$. Nine of the ten frozen-most counties are in Alaska; the tenth is Clear Creek County, Colorado. For counties with no weather stations, we impute the climate by averaging the values of the fraction of freezing days among adjacent counties. ${ }^{27}$ Figure C-1 shows the climate data for the lower 48 states.

Estimates of the net effect are presented in Table C-1. The first two columns show the first-stage and IV regression for the direct sample; the last two columns are for the full sample. The sample size is slightly smaller than in other cross-sectional specifications because we drop stations affected by self-service bans, for which climate is a poor predictor

\footnotetext{
${ }^{25}$ For an example in which a spatially correlated instrument is invalid, see Basker (2006).

${ }^{26}$ We weight February 29 as a quarter day.

${ }^{27}$ We use http://www.census.gov/geo/reference/docs/county_adjacency.txt to determine adjacency.
} 
of adoption.

Both first-stage regressions are strong. The interpretation of the coefficient of -3.7 in the direct sample is that comparing a station in a location without a self-service ban where the temperature is never below freezing to a station, also not affected by a ban, where the temperature is below freezing $25 \%$ of the days of the year (roughly the 25th and 75 th percentiles of the distribution of the variable across all U.S. counties), the latter station has on average $3.7 / 4$, or about one, fewer self-service pumps. The coefficient of -6.3 in the full sample indicates that for the larger sample of stations the difference is about 1.5 self-service pumps.

The point estimate of the direct employment effect is within $10 \%$ of the self-service ban IV, despite using a completely different identification strategy. The full effect is much smaller, around -0.12 workers per pump, but the large standard errors prevent us from identifying this effect with any precision.

\section{Self-Service vs. Full-Service Prices}

We use two external data price series, one from the Bureau of Labor Statistics (BLS) and the other from the American Chamber of Commerce Research Association, or ACCRA (today, the Council for Community and Economic Research, or C2ER), to estimate the full-service premium in $1982 .^{28}$

The BLS published a price series for "gasoline, unleaded regular, per gallon" including relevant excise taxes starting in 1976. The BLS price series does not specify a service level, and averages out both full-service and self-service outlets surveyed. (The series also combines cash and credit prices.) Because, as documented in this paper, almost all stations sold fullservice gasoline only at the beginning of the series, and over time more and more switched

\footnotetext{
${ }^{28}$ We thank CY Choi for help with the ACCRA data files.
} 
to the self-service model, the series likely represents a slow-moving weighted average of the full- and self-service prices.

ACCRA has published a quarterly cost-of-living index and component prices of several dozen products and services since 1968. Over the period 1976-1992, between 165 and 300 cities were included in the survey in any given quarter. Volunteers collected prices in the first week of every quarter (in January, April, July, and October) and were instructed to sample at least five outlets if possible and report the average price. The ACCRA product description for gasoline changed a few times over this period. At first, the product definition was simply "gasoline: regular grade, including taxes (national brand)." Starting in the fourth quarter of 1976, the product definition was revised to add the term "full service," evidence of the increasing adoption of the self-service model throughout the 1970s. In 1979Q2, the word "unleaded" was added to modify "regular grade." In 1982Q1, "full service" was replaced with "self service if available." Finally, in 1986Q1, ACCRA for the first time specified "cash price."

We exploit the abrupt transition from "full service" to "self service" in the ACCRA price series in contrast with the gradual transition in the BLS series to uncover the full-service price premium. The BLS price for the average U.S. city and the average reported ACCRA price are shown, at quarterly frequency, in the top panel of Figure D-1. The first vertical line, between the first and second quarter of 1979, separates the earlier period, during which the ACCRA prices may have been for leaded gasoline, with the later period, during which unleaded was specified. The second vertical line, between the last quarter of 1981 and the first quarter of 1982, marks the change from full-service to self-service prices. The bottom panel in Figure D-1 shows the nominal difference between the two series.

Prior to the second quarter of 1979, the difference between the BLS price and the average ACCRA price, representing the nominal "unleaded premium" in the BLS price, ranges from 1.5 to 3.5 cents, with an average of about 2.5 cents. Once "unleaded" is specified by ACCRA, the two series move together very closely: for five consecutive quarters, the difference between 
them averages a third of a cent. Then, in the third quarter of 1980, the ACCRA series starts breaking away from the BLS series, rising slowly, first by one cent, eventually by 5.5 cents. This trend is abruptly broken when ACCRA switches from full-service to self-service gasoline; for the next three years, the ACCRA price is 4.3-6.3 cents lower than the BLS price, averaging about 5.3 cents lower.

Because the ACCRA sample is time-varying, we confirm that the break between 1981Q4 and 1982Q1 is not due to a change in the sample. Excluding cities in New Jersey and Oregon (of which there are too few to form a meaningful separate sample), there are 227 cities in the 1981Q4 sample and 206 in the 1982Q1 sample; the two samples overlap for 189 cities in 41 states. For this subset of cities, the average ACCRA price is 5.5 cents higher than the BLS price in 1981Q4, and 4.4 cents lower the following quarter.

As the gap between the two series closes, the two prices are once again indistinguishable by mid-1989. This may not reflect a decrease in the full-service premium, however; over time, the BLS price includes more and more self-service outlets as the self-service model spreads, mechanically moving the BLS price towards the ACCRA price. 


\section{References}

Aaronson, D., E. French, and I. Sorkin (2013) "Firm Dynamics and the Minimum Wage: A Putty-Clay Approach," Federal Reserve Bank of Chicago Working Paper 2013-26.

Allvine, F. C., and J. M. Patterson (1974) Highway Robbery: An Analysis of the Gasoline Crisis. Indiana University Press, Bloomington, IN and London.

Autor, D. (2015) "Why Are There Still So Many Jobs? The History and Future of Workplace Automation," Journal of Economic Perspectives, 29(3), 3-30.

Autor, D. H., F. Levy, and R. J. Murnane (2002) "Upstairs, Downstairs: Computers and Skills on Two Floors of a Large Bank," Industrial and Labor Relations Review, 55(3), $432-447$.

(2003) "The Skill Content of Recent Technological Change: An Empirical Exploration," Quarterly Journal of Economics, 118(4), 1279-1333.

Baker, E. (1972) I Want to Be a Service Station Attendant. Childrens Press, Chicago.

Basker, E. (2006) "When Good Instruments Go Bad," unpublished paper, University of Missouri.

(2012) "Raising the Barcode Scanner: Technology and Productivity in the Retail Sector," American Economic Journal: Applied Economics, 4(3), 1-29.

Bessen, J. (2015) "Toil and Technology," Finance \& Development, 52(1), 16-19.

Betancourt, R. R. (2005) The Economics of Retailing and Distribution. Edward Elgar Publishing, Cheltenham, England, and Northampton, MA.

Blass, A. A., and D. W. Carlton (2001) "The Choice of Organizational Form in Gasoline Retailing and the Cost of Laws That Limit That Choice," Journal of Law and Economics, $44(2), 511-524$.

Borenstein, S. (1991) "Selling Costs and Switching Costs: Explaining Retail Gasoline Margins," RAND Journal of Economics, 22(3), 354-369.

Brynjolfsson, E., and A. McAfee (2014) The Second Machine Age: Work, Progress, and Prosperity in a Time of Brilliant Technologies. W. W. Norton \& Company, New York and London.

Clarion House (1968) Service Center Attendant: How Ted Learned His Job in a Service Station, Accent/Job Models. Chicago, Prepared for the Educational Opportunities Division of Follett Educational Corporation.

Foster, L., C. Grim, J. Haltiwanger, and Z. Wolf (2015) "Firm-Level Dispersion in Productivity: Is the Devil in the Details?," Working paper. 
Foster, L., J. Haltiwanger, and C. J. Krizan (2006) "Market Selection, Reallocation and Restructuring in the U.S. Retail Trade Sector in the 1990s," Review of Economics and Statistics, 88(4), 748-758.

Foster, L., J. Haltiwanger, and C. Syverson (2008) "Reallocation, Firm Turnover, and Efficiency: Selection on Productivity or Profitability?," American Economic Review, 98(1), $394-425$.

Goldmanis, M., A. Hortaçsu, C. Syverson, and O. Emre (2010) "E-Commerce and the Market Structure of Retail Industries," Economic Journal, 120(545), 651682.

Graetz, G., and G. Michaels (2015) "Robots at Work," unpublished paper, London School of Economics.

Haltiwanger, J. (forthcoming) "Firm Dynamics and Productivity: TFPQ, TFPR, and Demand Side Factors," Economia.

Hastings, J. (2004) "Vertical Relationships and Competition in Retail Gasoline Markets: An Empirical Evidence from Contract Changes in Southern California," American Economic Review, 94(1), 317-328.

Jarmin, R. S., and J. Miranda (2002) "The Longitudinal Business Database," unpublished paper, U.S. Census Bureau.

Johnson, R. N., and C. J. Romeo (2000) "The Impact of Self-Service Bans in the Retail Gasoline Market," Review of Economics and Statistics, 82(4), 625-633.

Kim, T. (2015) "Price Competition in Retail Gasoline: New Evidence from South Korea," unpublished paper, University of Missouri.

Lambert, C. (2015) Shadow Work: The Unpaid, Unseen Jobs that Fill Your Day. Counterpoint, Berkeley.

Lawrence, D. (1984) "Why C-Stores Lead Gasoline Markets: Can You Afford to Enter Crowded Field?," National Petroleum News, 76(4), 34-40.

Lindbeck, A., and S. Wikström (2003) "E-exchange and the Boundary between Households and Organizations," Kyklos, 56(3), 315-340.

Nassaney, D. (2013) Getting Hosed? Secrets, Confessions, and Tales from a Gas Station Owner. D \& C Publishing International.

Noel, M. D. (forthcoming) "Retail Gasoline Markets," in Handbook on the Economics of Retail and Distribution, ed. by E. Basker. Edward Elgar.

Oi, W. Y. (1992) "Productivity in the Distributive Trades: The Shopper and the Economies of Massed Reserves," in Output Measurement in the Service Sectors, ed. by Z. Griliches, pp. 161-193. University of Chicago Press, Chicago. 
Png, I., and D. Reitman (1994) "Service Time Competition," RAND Journal of Economics, 25(4), 619-634.

(1995) "Why are Some Products Branded and Others Not?," Journal of Law and Economics, 38(1), 207-224.

Ratchford, B. (forthcoming) "Retail Productivity," in Handbook on the Economics of Retail and Distribution, ed. by E. Basker. Edward Elgar.

Reid, M. (1984) "How the Self-Service Revolution Bred Price Wars and C-Stores," National Petroleum News, 76(2), 92-98.

Shepard, A. (1991) "Price Discrimination and Retail Configuration," Journal of Political Economy, 99(1), 30-53.

- (1993) "Contractual Form, Retail Price, and Asset Characteristics in Gasoline Retailing," RAND Journal of Economics, 24(1), 58-77.

Solomon, C. (1993) "Transportation: Self-Service At Gas Stations Includes Paying," Wall Street Journal, August 4, B1.

Staiger, D., and J. H. Stock (1997) "Instrumental Variables Regression with Weak Instrument," Econometrica, 65(3), 557-586.

Tulsa Business Chronicle (1985) "Phillips Testing Credit Card-Operated Pumps in Tulsa," Tulsa Business Chronicle, July 29, 7.

Vandegrift, D., and J. A. Bisti (2001) "The Economic Effects of New Jersey's Self-Serve Operations Ban on Retail Gasoline Markets," Journal of Consumer Policy, 24(1), 63-81.

Wall Street Journal (1983) "Conna Automates Gasoline Stations with Payment System," Wall Street Journal, August 10.

Wall Street Journal (1983) "Bank of America, Arco Slate Credit-Card Test," Wall Street Journal, August 23. 


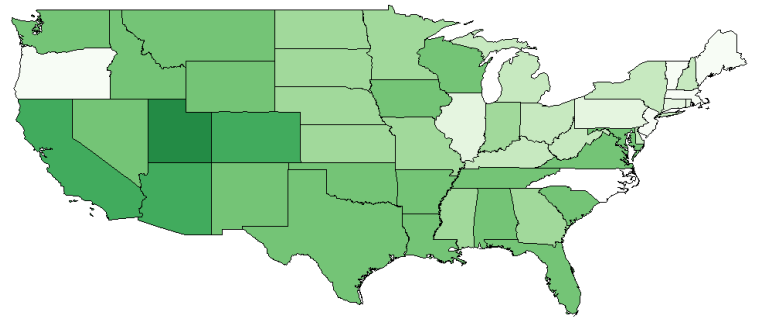

(a) 1977

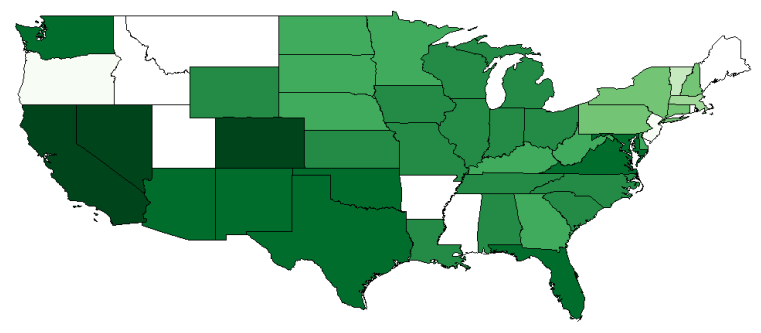

(c) 1987

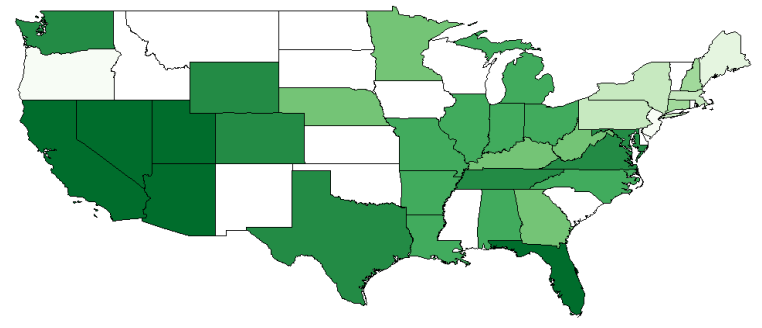

(b) 1982

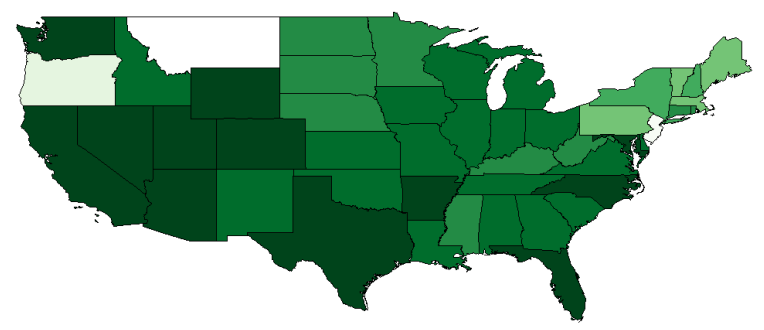

(d) 1992

\section{$[0, .1] \square(.1,2] \square(2,3] \square(3,4] \square(.4,6]$ \\ $(6,7] \square(.7,8]$ \\ $(8,9]$ \\ $0.1] \square$ No data}

Figure 1. Fraction of Stations Offering Self Service, by State

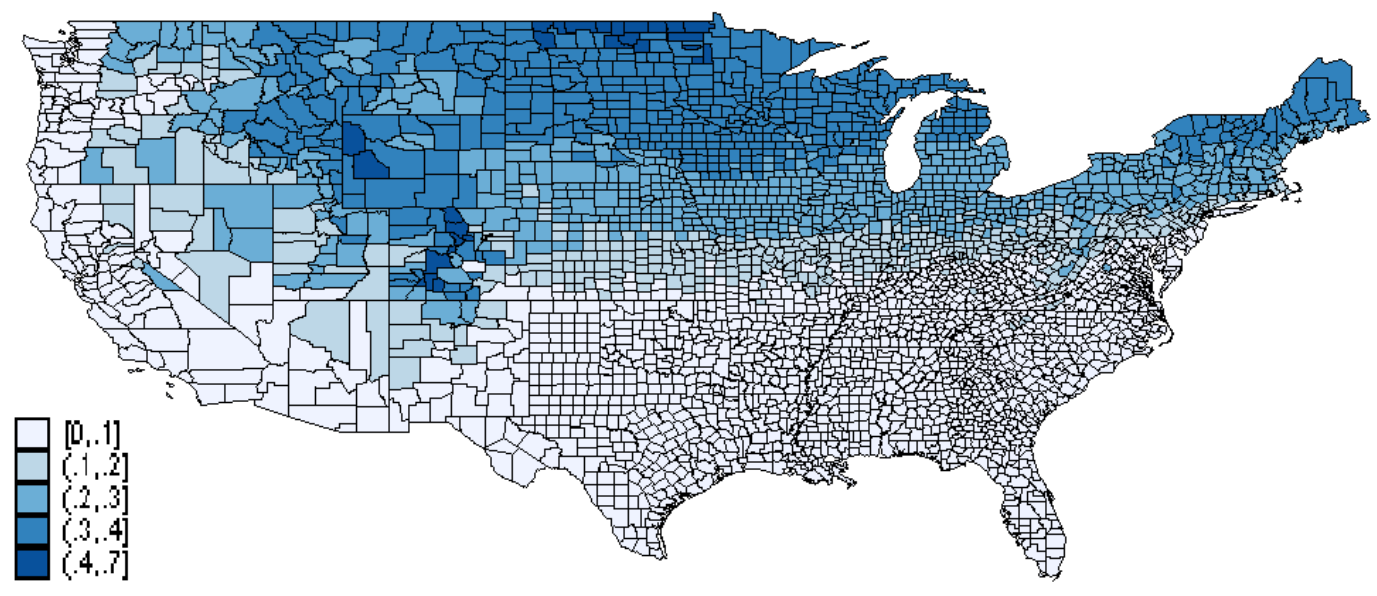

Figure C-1. Fraction of Year with Below-Freezing Average Daily Temperature 


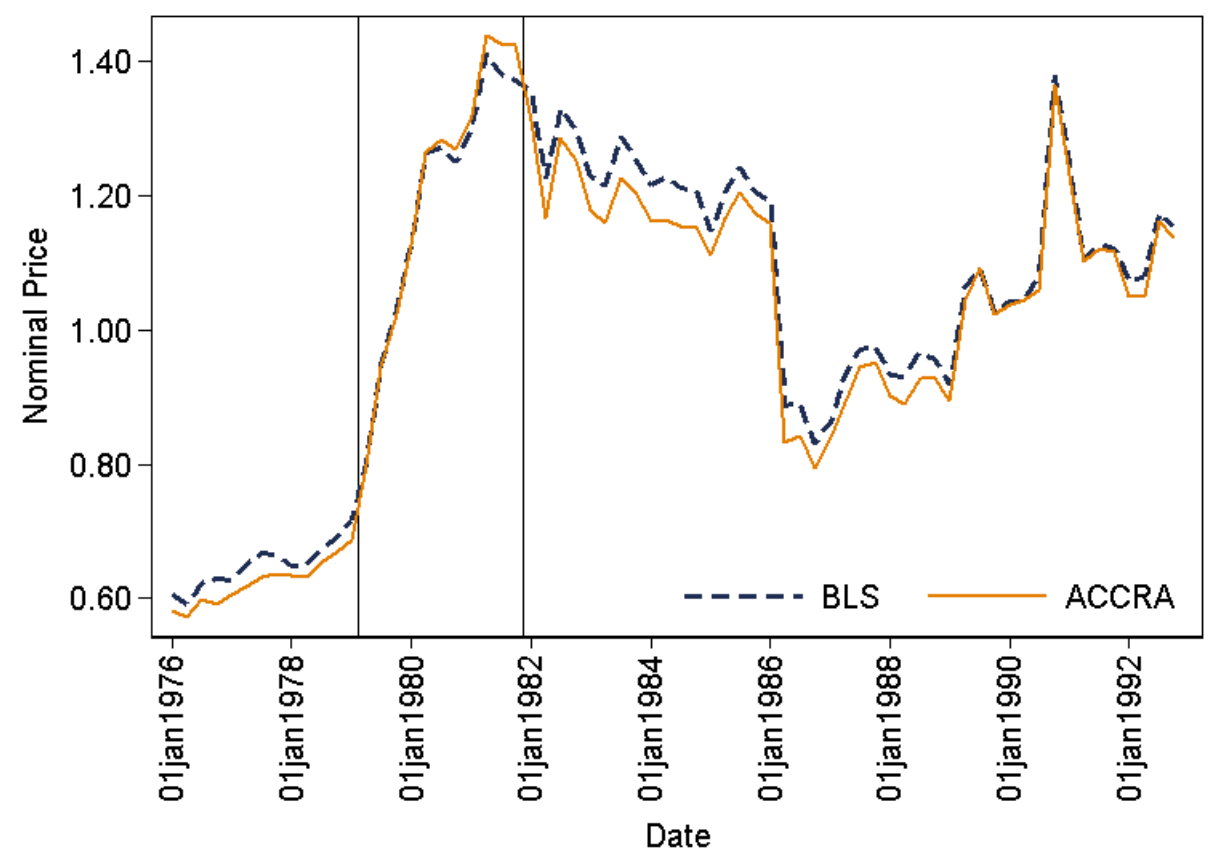

(a) Nominal BLS and ACCRA prices

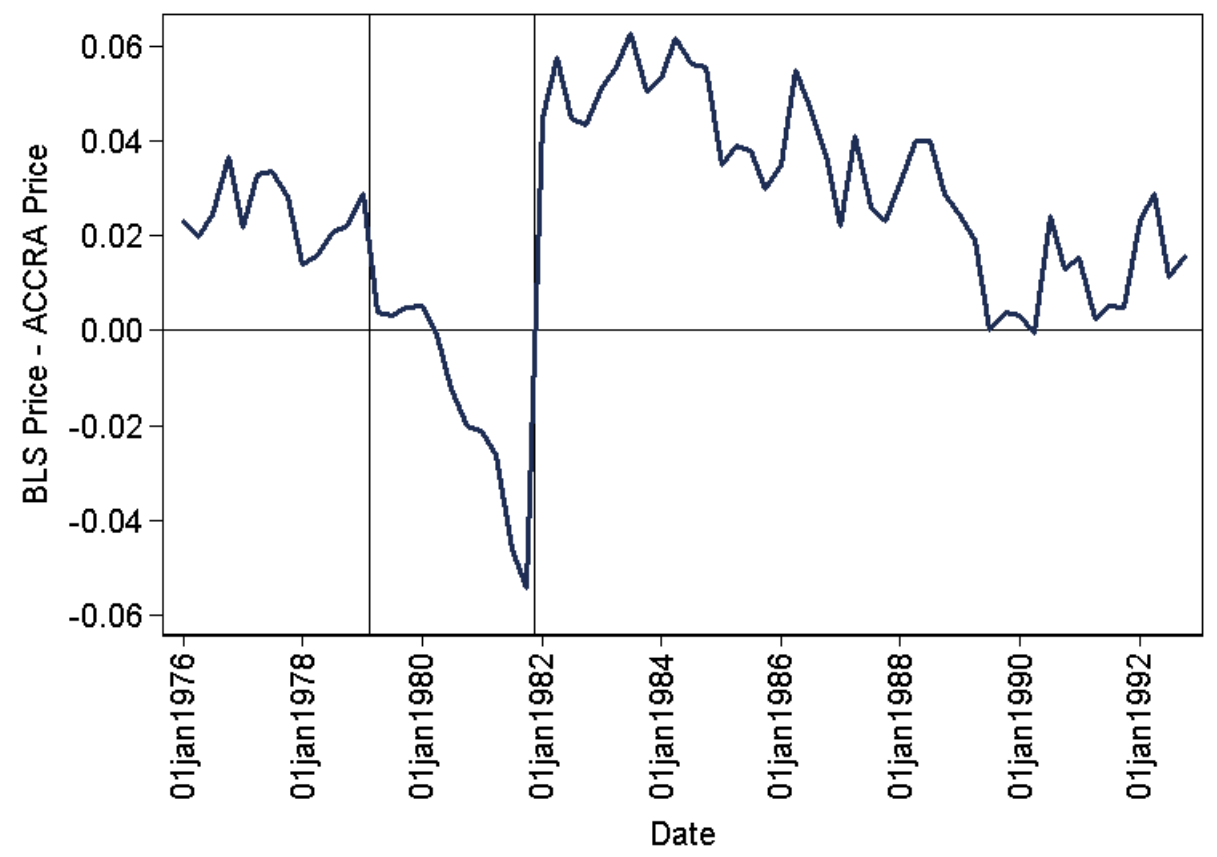

(b) Nominal Price Difference

Figure D-1. BLS and ACCRA Average Nominal Prices for Gasoline 
Table 1. Trends in the Gas-Station Sector, 1972-1997

\begin{tabular}{lccrrrr}
\hline & 1972 & 1977 & 1982 & 1987 & 1992 & \multicolumn{1}{c}{1997} \\
\hline \hline Gas stations (SIC 554) & 183,385 & 146,523 & 116,188 & 114,748 & 105,334 & 98,846 \\
Convenience stores selling gas & & & & & & \\
$\quad$ (SIC 541130) & $\mathrm{n} / \mathrm{a}$ & 5,138 & 13,390 & 20,293 & 23,065 & 28,043 \\
All locations selling gas & $\mathrm{n} / \mathrm{a}$ & 151,661 & 129,578 & 135,041 & 128,339 & 126,889 \\
\hline Gas-station employment $^{\mathrm{a}}$ & 747,668 & 672,673 & 603,886 & 701,690 & 675,080 & 741,040 \\
Average station employment $^{\mathrm{a}}$ & 4.1 & 4.6 & 5.2 & 6.2 & 6.4 & 7.5 \\
\hline Self service (\% of stations) $^{\mathrm{a}}$ & 8.2 & 38.3 & 58.7 & 70.5 & 79.9 & $\mathrm{n} / \mathrm{a}$ \\
\hline
\end{tabular}

Source: authors' calculations from published and unpublished CRT data

Figures refer to stations with payroll

a SIC 554 only

Table 2. Summary Statistics for Regression Samples

\begin{tabular}{|c|c|c|c|c|c|}
\hline & \multicolumn{5}{|c|}{ A. Direct Samples ${ }^{a}$} \\
\hline & \multirow[b]{2}{*}{ Pooled } & \multicolumn{3}{|c|}{ Border } & \multirow[b]{2}{*}{ Panel $^{\mathrm{a}, \mathrm{b}}$} \\
\hline & & 5 Miles & 10 Miles & 20 Miles & \\
\hline Stations $^{\mathrm{c}}$ & 31,900 & 700 & 1,300 & 1,900 & 1,400 \\
\hline Observations $^{\mathrm{c}}$ & 38,200 & 900 & 1,600 & 2,300 & 2,900 \\
\hline Average Employment & 5.0 & 6.3 & 6.0 & 6.2 & 4.5 \\
\hline Average Pumps & 7.4 & 6.9 & 6.9 & 7.2 & 6.6 \\
\hline Self service (\%) & 54.4 & 23.4 & 22.1 & 22.4 & 54.5 \\
\hline Average Self-service pumps ${ }^{\mathrm{d}}$ & 7.2 & 7.3 & 7.2 & 7.6 & 6.8 \\
\hline Age $\geq 2(\%)$ & 85.9 & 92.1 & 91.5 & 91.3 & 90.5 \\
\hline
\end{tabular}

\begin{tabular}{|c|c|c|c|c|c|}
\hline & \multirow[b]{2}{*}{ Pooled } & \multicolumn{3}{|c|}{ Border $^{a}$} & \multirow[b]{2}{*}{ Panel } \\
\hline & & 5 Miles & 10 Miles & 20 Miles & \\
\hline Stations $^{\mathrm{c}}$ & 121,000 & 1,800 & 3,400 & 5,000 & 36,500 \\
\hline Observations $^{\mathrm{c}}$ & 172,100 & 2,500 & 4,700 & 7,100 & 87,600 \\
\hline Average Employment & 6.3 & 6.3 & 6.1 & 6.2 & 6.7 \\
\hline Average Pumps & 7.8 & 7.0 & 6.9 & 7.0 & 8.2 \\
\hline Self service $(\%)$ & 64.2 & 26.2 & 23.3 & 23.8 & 69.9 \\
\hline Average Self-service pumps ${ }^{\mathrm{d}}$ & 7.2 & 7.8 & 7.5 & 7.5 & 7.5 \\
\hline Age $\geq 2(\%)$ & 90.3 & 93.6 & 93.6 & 93.3 & 92.9 \\
\hline Convenience $(\%)^{\mathrm{e}}$ & 51.0 & 23.9 & 22.5 & 23.0 & 54.0 \\
\hline Repair $(\%)^{\mathrm{e}}$ & 47.8 & 52.2 & 55.5 & 57.0 & 42.6 \\
\hline
\end{tabular}

${ }^{a}$ Exclude stations with convenience stores or repair shops

b Exclude stations with variable number of pumps

${ }^{c}$ Rounded to the nearest hundred

d Stations with self-service pumps only

e Stations reporting revenue breakdown only 
Table 3. Direct Effect of Self Service on Employment

\begin{tabular}{|c|c|c|c|c|}
\hline & \multicolumn{2}{|c|}{ Pooled Cross Section } & \multicolumn{2}{|r|}{ Panel } \\
\hline & OLS & $\begin{array}{c}\text { IV } \\
\text { (Self-Service Ban) }\end{array}$ & OLS & $\begin{array}{c}\text { IV } \\
(\text { SS Ban } \times \text { Time })\end{array}$ \\
\hline Pumps ${ }^{s s}$ & $\begin{array}{l}-0.249^{* * *} \\
(0.033)\end{array}$ & $\begin{array}{l}-0.441^{* * *} \\
(0.026)\end{array}$ & $\begin{array}{l}-0.129^{* * *} \\
(0.046)\end{array}$ & $\begin{array}{l}-0.065 \\
(0.180)\end{array}$ \\
\hline Stations $^{\mathrm{a}}$ & 31,900 & 31,900 & 1,400 & 1,400 \\
\hline Observations $^{\mathrm{a}}$ & 38,200 & 38,200 & 2,900 & 2,900 \\
\hline
\end{tabular}

Border Samples ${ }^{\mathrm{b}}$

\begin{tabular}{|c|c|c|c|c|c|c|}
\hline \multirow{2}{*}{$\begin{array}{r}\text { Max. distance } \\
\text { from border: }\end{array}$} & \multicolumn{3}{|c|}{ OLS } & \multicolumn{3}{|c|}{ Fuzzy Regression Discontinuity } \\
\hline & 5 Miles & 10 Miles & 20 Miles & 5 Miles & 10 Miles & 20 Miles \\
\hline Pumps $^{s s}$ & $\begin{array}{l}-0.325^{* * *} \\
(0.086)\end{array}$ & $\begin{array}{l}-0.295^{* *} \\
(0.112)\end{array}$ & $\begin{array}{l}-0.290^{* * *} \\
(0.077)\end{array}$ & $\begin{array}{l}-0.143 \\
(0.126)\end{array}$ & $\begin{array}{l}-0.448^{* * *} \\
(0.131)\end{array}$ & $\begin{array}{l}-0.457^{* * *} \\
(0.043)\end{array}$ \\
\hline Stations $^{\mathrm{a}}$ & 700 & 1,300 & 1,900 & 700 & 1,300 & 1,900 \\
\hline Observations $^{\mathrm{a}}$ & 900 & 1,600 & 2,300 & 900 & 1,600 & 2,300 \\
\hline
\end{tabular}

Samples exclude stations with convenience stores and/or repair services. All regressions include year fixed effects, number of pumps, and indicators for vertically integrated owner and for station age $\geq 2$. Panel regressions also include station fixed effects. Crosssectional and border regressions include chain fixed effects, and border regressions also include five region indicators, and distance from the border interacted with state.

${ }^{a}$ Rounded to the nearest hundred

b Samples include stations in New Jersey, Oregon, and surrounding states, within a fixed distance from the NJ or OR borders.

Robust standard errors in parentheses, clustered by state

$* \mathrm{p}<10 \%$; ** $\mathrm{p}<5 \%$; *** $\mathrm{p}<1 \%$ 
Table 4. Full Effect of Self Service on Employment

\begin{tabular}{lccccc}
\hline & \multicolumn{2}{c}{ Pooled Cross Section } & & \multicolumn{2}{c}{ Panel } \\
\cline { 2 - 3 } \cline { 5 - 6 } & OLS & (Self-Service Ban) & & OLS & (SS Ban $\times$ Time) \\
\hline \hline Pumps $^{\text {ss }}$ & $0.129^{* * *}$ & $-0.130^{* * *}$ & & $0.041^{* * *}$ & $-0.223^{* *}$ \\
& $(0.017)$ & $(0.041)$ & & $(0.011)$ & $(0.096)$ \\
\hline Stations $^{\mathrm{a}}$ & 121,000 & 121,000 & & 36,500 & 36,500 \\
Observations $^{\mathrm{a}}$ & 172,100 & 172,100 & & 87,600 & 87,600 \\
\hline
\end{tabular}

Border Samples ${ }^{\mathrm{b}}$

\begin{tabular}{|c|c|c|c|c|c|c|}
\hline \multirow{2}{*}{$\begin{array}{l}\text { Max. distance } \\
\text { from border: }\end{array}$} & \multicolumn{3}{|c|}{ OLS } & \multicolumn{3}{|c|}{ Fuzzy Regression Discontinuity } \\
\hline & 5 Miles & 10 Miles & 20 Miles & 5 Miles & 10 Miles & 20 Miles \\
\hline Pumps $^{s s}$ & $\begin{array}{l}-0.320^{* * *} \\
(0.076)\end{array}$ & $\begin{array}{l}-0.304^{* * *} \\
(0.058)\end{array}$ & $\begin{array}{l}-0.264^{* * *} \\
(0.069)\end{array}$ & $\begin{array}{c}0.260^{* *} \\
(0.117)\end{array}$ & $\begin{array}{l}-0.349 \text { *** } \\
(0.068)\end{array}$ & $\begin{array}{l}-0.408^{* * *} \\
(0.042)\end{array}$ \\
\hline Stations $^{\mathrm{a}}$ & 1,800 & 3,400 & 5,000 & 1,800 & 3,400 & 5,000 \\
\hline Observations $^{\mathrm{a}}$ & 2,500 & 4,700 & 7,100 & 2,500 & 4,700 & 7,100 \\
\hline
\end{tabular}

All regressions include year fixed effects, and indicators for vertically integrated owner and for station age $\geq 2$. Panel regressions also include station fixed effects, and border regressions include chain fixed effects, five region indicators, and distance from the border interacted with state.

${ }^{a}$ Rounded to the nearest hundred

b Samples include stations in New Jersey, Oregon, and surrounding states, within a fixed distance from the NJ or OR borders.

Robust standard errors in parentheses, clustered by state

${ }^{*} \mathrm{p}<10 \%$; ${ }^{* *} \mathrm{p}<5 \%$; *** $\mathrm{p}<1 \%$ 
Table B-1. First-Stage Results: Pooled and Panel Samples

\begin{tabular}{llllll}
\hline & \multicolumn{2}{c}{ Pooled Cross Section } & & \multicolumn{2}{c}{ Panel $^{\mathrm{b}}$} \\
\cline { 2 - 3 } \cline { 5 - 6 } & \multicolumn{1}{c}{ Direct } & \multicolumn{1}{c}{ Full } & & Direct & Full \\
\hline \hline SS Ban & $-5.428^{* * *}$ & $-4.042^{* * *}$ & & \\
& $(0.555)$ & $(0.316)$ & & \\
\hline SS Ban $\times$ Time & & & & $-1.013^{* * *}$ & $-1.361^{* * *}$ \\
& & & & $(0.195)$ & $(0.126)$ \\
\hline F statistic & 95.75 & 163.97 & & 26.96 & 116.69 \\
\hline Stations $^{\mathrm{a}}$ & 31,900 & 121,000 & & 1,400 & 36,500 \\
Observations $^{\mathrm{a}}$ & 38,200 & 172,100 & & 2,900 & 87,700 \\
\hline
\end{tabular}

Endogenous LHS variable is number of self-service pumps

Pooled cross-sectional regressions include year fixed effects, number of pumps (direct sample only), vertical-integration indicator (full sample) or chain fixed effects (direct sample), and an indicator for station age $\geq 2$. Panel regressions include year and station fixed effects, and indicators for vertical integration and for station age $\geq 2$.

${ }^{a}$ Rounded to the nearest hundred

b Sample excludes stations affected by self-service bans

Robust standard errors in parentheses, clustered by state

${ }^{*} \mathrm{p}<10 \%$; ** $\mathrm{p}<5 \%$; ** $\mathrm{p}<1 \%$

Table B-2. First-Stage Results: Fuzzy Regression Discontinuity Sample

\begin{tabular}{cccccccc}
\hline & \multicolumn{3}{c}{ Direct } & & \multicolumn{3}{c}{ Full } \\
\cline { 2 - 4 } \cline { 6 - 8 } $\begin{array}{c}\text { Max. distance } \\
\text { from border: }\end{array}$ & 5 Miles & 10 Miles & 20 Miles & & 5 Miles & 10 Miles & 20 Miles \\
\hline \hline SS Ban & $-6.599^{* * *}$ & $-4.870^{* * *}$ & $-4.300^{* * *}$ & & $-6.515^{* * *}$ & $-5.075^{* * *}$ & $-4.833^{* * *}$ \\
& $(1.481)$ & $(0.807)$ & $(0.608)$ & & $(0.442)$ & $(0.896)$ & $(1.208)$ \\
\hline F statistic & 19.86 & 36.40 & 49.95 & & 217.71 & 32.10 & 16.00 \\
\hline Stations $^{\mathrm{a}}$ & 700 & 1,300 & 1,900 & & 1,800 & 3,400 & 5,000 \\
Observations $^{\mathrm{a}}$ & 900 & 1,600 & 2,300 & & 2,500 & 4,700 & 7,100 \\
\hline
\end{tabular}

Endogenous LHS variable is number of self-service pumps

Regressions include year and chain fixed effects, five region indicators, distance from the border interacted with state, number of pumps (direct sample only), and an indicator for station age $\geq 2$.

${ }^{\text {a }}$ Rounded to the nearest hundred

Robust standard errors in parentheses, clustered by state

$* \mathrm{p}<10 \%$; $* * \mathrm{p}<5 \%$; *** $\mathrm{p}<1 \%$ 
Table C-1. Direct Effect of Self Service on Employment: Climate IV using Pooled Cross Section

\begin{tabular}{|c|c|c|c|c|}
\hline & \multicolumn{2}{|c|}{ Direct Effect } & \multicolumn{2}{|c|}{ Full Effect } \\
\hline & First Stage & Employment & First Stage & Employment \\
\hline Freezing Days & $\begin{array}{l}-3.690^{* * *} \\
(0.807)\end{array}$ & & $\begin{array}{l}-6.317^{* * *} \\
(1.465)\end{array}$ & \\
\hline Pumps ${ }^{s s}$ & & $\begin{array}{l}-0.413^{* *} \\
(0.184)\end{array}$ & & $\begin{array}{l}-0.122 \\
(0.215)\end{array}$ \\
\hline F statistic & 20.91 & & 18.58 & \\
\hline Stations $^{\mathrm{a}}$ & 29,800 & 29,800 & 115,700 & 115,700 \\
\hline Observations $^{\mathrm{a}}$ & 35,700 & 35,700 & 165,100 & 165,100 \\
\hline
\end{tabular}

Samples excludes stations subject to self-service bans.

All regressions include year fixed effects and an indicator for station age $\geq 2$. Direct regressions also include chain fixed effects and number of pumps; full regressions include a vertical integration indicator.

${ }^{\text {a }}$ Rounded to the nearest hundred

Robust standard errors in parentheses, clustered by state

$* \mathrm{p}<10 \%$; ** $\mathrm{p}<5 \%$; *** $\mathrm{p}<1 \%$ 